\title{
Environmental Decision-Making Shaped by the Home: Situating Consumption in the Household
}

\author{
William Lytle ${ }^{1}$ \\ Department of Social Sciences, Michigan Technological University, United States \\ Chelsea Schelly \\ Department of Social Sciences, Michigan Technological University, United States \\ Kristin Floress \\ USDA Forest Service-Northern Research Station, Illinois, United States \\ Rachael L. Shwom \\ Department of Human Ecology, Rutgers University, New Jersey, United States \\ Kathleen E. Halvorsen \\ Research Development Department, Department of Social Sciences, College of Forest \\ Resources and Environmental Sciences, Michigan Technological University, United States
}

\section{Abstract}

Research on environmentally consequential human decision-making often begins from the premise that consumption decisions are motivated by individual values. However, we argue that social science research aiming to understand consumer decision-making will benefit from integrating the lived experiences of people in households, where decisions are often influenced or mitigated by the presence of those who share homes. Conducting research on consumption decisions regarding household resources revealed the embedded nature of these decisions, which are situated in the context of the socially contingent dynamics of residential life. In this paper, we identify five social dynamic processes that influence consumption within the household: (1) referring, (2) norming, (3) enhancing, (4) constraining, and (5) allocating. These processes, embedded within the dynamic social relationships of the residential household, moderate household resource use in ways that future social science research may strive to better understand.

Keywords: consumption, environmental decision-making, environmentally responsible behavior

1 Corresponding author: wjlytle@mtu.edu. 


\section{Introduction}

The average resident in the United States consumes significantly more natural resources than those living in other comparably developed nations (Chow et al., 2003; OECD, 2016). To understand environmentally consequential consumer choices and the potential for reducing the impacts of such consumption, researchers often turn to measures of individual knowledge, values, beliefs, and attitudes, presuming that consumption decisions are based on some combination of these factors (Dietz et al., 2009).

However, the research presented here suggests that consumption practices are embedded and negotiated within the physical and social household context, likely shaping both attitudes and behaviors. The ways in which household members have shaped each other's behaviors has been studied for decades, and this approach is closely aligned with theories of social practice (Spaargaren et al., 2016) and involves a variety of practice-based considerations that guide researchers' choices (Sharma $\&$ Ruud, 2003; Strengers et al., 2016). Social practice theories recognize the role of the built environment in shaping and constraining household practice choices (Warde, 2005). In this paper, we present evidence supporting a practice theory perspective: both the physical and social environment of the home shape household consumption practices.

The average American consumer will likely spend some part of their life as a child in a home with one or more adults and some part of their life as an adult sharing their home with one or more other adults and one or more children. In the 2018 census, 72 percent of Americans lived in a home with at least one other person (United States Census Bureau, 2018). As household composition shifts, so will resource consumption. Many of us have experienced firsthand the ways that parents, partners, children, and pets may shape our household practices, either by encouraging us to reduce consumption or by limiting the extent to which we can change our consumption behavior out of concern for someone else's needs, comforts, or preferences.

In this paper, we examine ways in which factors often relegated to "context" are potentially larger contributors to decision-making in a household than more dominant theories of environmental behaviors. We argue that environmental behavior research must more fully incorporate how household dynamics, specifically social dynamics, contribute to environmentally consequential consumption practices. This paper is based on interviews with American householders and aims to understand the values, motivations, opportunities, and barriers associated with current and potential future household consumption of food, energy, and water resources. Throughout the paper, we use the language of "household dynamics" because we recognize that many households may be composed of socially, legally, 
and institutionally constructed family units, often more diversified than nuclear family units. This is particularly true when we consider the role that past household members (such as deceased spouses, as described below) can have in shaping both attitudes and behaviors regarding environmentally consequential practices.

\section{Research on environmental decision-making}

There are multiple social science theories utilized to explain what drives different types of environmental practices (e.g., Shwom \& Lorenzen, 2012; Stern, 2014; Wilson \& Dowlatabadi, 2007). Research in social psychology has sought to understand individual values, norms, beliefs, and attitudes and their link to environmentally consequential consumer behavior. However, the vast majority of this work draws from paradigms of consumption emerging from economics and psychology, which emphasize individualistic decision-making and identify social influences as merely external to the decision-making process (Shove, 2010). Becker (1998) may recognize that using the individual as the unit of analysis, rather than a unit that corresponds with the lived experience of the family or household, perpetuates the flawed imagery that individual attitudes, behaviors, and choices should be the focal point of research designs related to environmentally consequential decisions. Almost 50 years ago, Davis expressed discomfort with the focus on individuals, writing: "the view of consumers as individual decision makers is still very much alive despite commonsense observations that the family is the relevant decision-making unit and a growing research interest in the field" (Davis, 1976, p. 242).

Shove (2010) describes much of the environmental decision-making and consumption research from this orientation to be characterized by the " $\mathrm{ABC}$ " model of consumption, in which " $\mathrm{A}$ " stands for attitude, "B" for behavior, and "C" for choice. The main argument made by Shove (2010) regarding the ABC model of consumption is that individual attitudes are presumed to influence behavioral intentions, ultimately influencing actual behavioral choices. She contends this presumption is flawed at best and, at worst, consequentially misleading for decision-makers regarding how to understand consumer behavior. This debate regarding the role of values, norms, beliefs, knowledge, and attitudes in shaping behavior is long-standing. The presumptions have held over decades of scholarship (e.g., Ajzen, 1991; Bamberg \& Möser, 2007; Fishbein et al., 1980; Hines et al., 1987) but have done very little to advance our ability to understand, predict, or change consumption choices (Heberlein, 2012). Black et al. (1985) suggest that understanding household energy consumption using survey methodology must go beyond bivariate analysis; it requires multivariate analyses that include contextual variables and social dynamics. Bolstering theories of decision-making with broader contextual information helps to develop explanations for how consumers make choices (Shwom \& Lorenzen, 2012). 
Considering relationships, role models, social dynamics, and lifestyle identities may enhance the knowledge gained through studying theories of planned behavior, theories of practice, and value-belief-norm models. Kennedy et al. (2009) keenly note that household variables, or the factors that are bigger than an individual in the home such as income, support network, and available time, may explain the gap between people's environmental values and environmentally responsible behaviors. Holdert and Antonides (1997) describe how a person's role in the household moderates their influence over certain stages and types of decision-making, with differences seen in traditional and modern family structures. Davis (1976) says that when you are investigating who decides something for the household, it is not only internal roles, how invested individuals are in the decision, or cultural expectations that impact the weight of their opinions, but also education and occupational status. With an expanded unit of analysis, we ask not only how the individual functions within the community, but also how the community itself functions. In pursuit of understanding the community, Staats et al. (2004) found groups with strong social influence and social support for environmental behaviors helped produce durable interventions to targeted behaviors.

\section{Methods}

In the summer of 2017, interviews were conducted with 44 residential dwellers in a suburban county outside a major metropolitan area in the Midwestern United States. A wide range of recruiting efforts (social media, public posters, information packets delivered to homes, face-to-face) were undertaken in the county that referred potential participants to the study and a form to input their contact information. These interviews were conducted in association with a much larger research project examining and ultimately aiming to make food, energy, and water consumption more sustainable in the residential home (Watkins et al., 2019). The interviews were conducted as exploratory research into the motivations for and challenges of shifting behaviors to reduce the negative environmental impacts associated with residential consumption patterns.

Most interviews took place within the participant's home and many were punctuated with a tour of their property. Each interview lasted approximately one hour and was recorded and fully transcribed. There was no structured collection of sociodemographic data, but following the interview participants were asked for recommendations of other people they knew who may be willing to discuss their consumption. This would often result in an informal listing of names and connections to neighbors, coworkers, friends, family, and organizational members. Recommendations of people with differing lifestyles, perspectives, and household composition were actively pursued to ensure data saturation. 
Data processing included inductive open coding of each transcript, focused on the challenges of changing environmentally consequential consumption in the home aligned with an interpretive grounded theory approach (Charmaz, 2014; Sebastian, 2019). This analysis revealed the importance of household composition and dynamics and the need to view households as holistic units for analysis rather than as comprised of discrete individual decision-makers.

This exploratory research was designed based on the most typical methodological approach to studying consumption behaviors: by asking individuals about their behavioral patterns and what motivates them. Interviews with individuals focused on decisions in the home and the contexts that shaped environmentally consequential consumption choices. Examples of the open-ended interview questions about specific resource consumption and household contexts include:

Can you begin by telling us a little bit about your home?

Do you think you use a little or a lot of [food, energy, or water]?

Do you try to reduce your resource [food, energy, or water] use at home? If so, how?

Are there things you wish you could do to reduce your [food, energy, or water] consumption, but can't?

Thinking about [food, energy, or water], what kinds of changes do you think would be easiest for your family to implement to reduce consumption?

What kinds of changes would be the hardest?

What kind of impacts do you associate with your [food, energy, or water] consumption?

\section{Results: Environmental practices with others in the home}

It was only through emergent data analysis that the importance of locating individuals within the context of the household became clear. Among the participants in this study, almost every interview included discussion of the role other household members played in shaping resource consumption. An example of the influence of household dynamics are highlighted in responses to the question, "What do you think are the biggest contributors to your water use at home?" We thought this question would help gauge the basic cognitive understanding of the participants regarding household consumption, with expected answers such as toilets, laundry, swimming pool, and perhaps indirect consumption via diet preference. Their answers varied greatly, as some participants cited the biggest contributors to be persons within the home (e.g., Mark), practices (e.g., Mark taking a bath), or objects (e.g., the bathtub). In some cases, participants were describing the social dynamics that lead 
to consumption in the household to reduce their personal responsibility, but many descriptions of social dynamics appeared to have the intent of accurately portraying their lived experience in the household, not as a means obfuscating blame.

Five social dynamic processes are outlined in Table 1: (1) preferring, (2) norming, (3) enhancing, (4) constraining, and (5) allocating. These processes may overlap in certain scenarios and are not intended to be either exclusive or exhaustive. The processes are described and accompanied by an example quotation that appears with additional context later in the results. The five processes represent recurring themes in the data that build upon traditional understandings of "context" within individual decision-making models.

Table 1. Five social dynamic processes that influence household consumption.

\begin{tabular}{|l|l|l|}
\hline Process & Description & Example Quotation \\
\hline (1) preferring & $\begin{array}{l}\text { individual preferences or } \\
\text { requirements dictate group } \\
\text { behavior }\end{array}$ & $\begin{array}{l}\text { "My wife has allergies and you can't leave the } \\
\text { window open." }\end{array}$ \\
\hline (2) norming & $\begin{array}{l}\text { internal family social norms } \\
\text { insulate individual behaviors }\end{array}$ & $\begin{array}{l}\text { "I have three other people in this family who like } \\
\text { to sit in a tub or take a long hot shower. Can I talk } \\
\text { them out of it?" }\end{array}$ \\
\hline (3) enhancing & $\begin{array}{l}\text { enhancing or supporting other } \\
\text { members' efforts to be more } \\
\text { sustainable }\end{array}$ & $\begin{array}{l}\text { "I am trying to like vegetables. My wife loves } \\
\text { them, she makes a lot of salads but I am not that } \\
\text { fond of it, but I am trying to." }\end{array}$ \\
\hline (4) constraining & $\begin{array}{l}\text { constraining or deterring other } \\
\text { members' efforts to be more } \\
\text { sustainable }\end{array}$ & $\begin{array}{l}\text { "I don't think we need to wash the clothes as } \\
\text { much as we do but my sister has a habit of just } \\
\text { washing them." }\end{array}$ \\
\hline (5) allocating & $\begin{array}{l}\text { decision-making or practices } \\
\text { are allocated to another } \\
\text { member of the household }\end{array}$ & $\begin{array}{l}\text { "The easiest [thing we do to conserve resources } \\
\text { at home], and this is going to sound goofy, is I do } \\
\text { everybody's laundry." }\end{array}$ \\
\hline
\end{tabular}

Source: Authors' summary.

The only interviewees who did not discuss the role of household dynamics in shaping resource consumption in their own homes were those who lived alone, but almost all of those who lived alone discussed the role of household composition in shaping resource use, either through reference to their own past experience or through reference to friends and neighbors whose behavior is at least partially shaped through interactions and compromises among household members. Interviewees with children mentioned the role of children in shaping household consumption through behaviors and expectations; even people whose spouses had passed away mentioned their continued influence on their consumption behaviors, and people who lived with adults other than spouses (such as adult siblings living together) discussed the role of other adults in the home in shaping household resource use. One participant described how the decisions made for the household in the past shaped their current consumption: 
When I retired, I put the addition on the house for my mother and my mother-inlaw. But while I started the addition, the wife died. And then the mother-in-law went to live with her son in California. And my mother died. So, I am sitting here with a four-bedroom house by myself.

In other words, although they were asked about their individual motivations and choices, almost every single participant demonstrated that the individual is not the sole unit of analysis for understanding residential consumption behaviors.

Some married participants discussed how their spouse limited or enhanced household efforts to be efficient consumers. For example, one said:

From my standpoint, and you will understand this if you are married. Your wife is probably cold all of the time and you are hot. She wants it $75^{\circ} \mathrm{F}\left[24^{\circ} \mathrm{C}\right]$ and you want it $65^{\circ} \mathrm{F}\left[18^{\circ} \mathrm{C}\right]$ so obviously the people that live in the household have different internal thermometers.

The same interviewee also said: "I don't have a problem keeping the house cool in the winter and I don't have a problem leaving the windows open on warmer nights, with the fan ... [but] my wife has allergies and you can't leave the window open then." Other interviewees, instead of having wives who preferred a warmer heating setting, claimed that they used more energy in thermal cooling "because my wife likes it cool." When asked about the biggest challenge to reducing resource consumption at home, one participant said, "The hardest is trying to get my wife on board." Later, when discussing specifically the possibilities for reduction in water usage, the same interviewee said, "Showers [would be hard to reduce], hot showers. Tell my wife. The easiest is to not get in that fight." Yet the same participant acknowledged that their wife also has some preferences for what was perceived as more environmentally responsible consumption that they do not share: "My wife will try to buy organic. I will look at costs. I am not going to spend eight bucks on a dozen eggs when I can get them for two. That's not going to happen."

In other words, married individuals recognized the role of their spouse in shaping resource consumption at home; however, the extent to which they increased or decreased the environmental impacts of consumption depended on the particular person, the particular resource, and the interpretive perception of the interviewee. For example, one participant said that their partner's practices were constraining conservation efforts, "I think, particularly for my husband, turning things off that he is not using is probably one of the hardest things for him. He'll start watching TV and then he will get distracted doing something else and leave the TV going." Another said, "My wife likes gardening a lot and when it gets dry she does use a lot of water." Yet they also acknowledged that their wife also influences food choices based upon her preference: "I am trying to like vegetables. My wife loves them, she makes a lot of salads but I am not that fond of it, but I am trying to." Others also described how their spouses encouraged or enhanced resource conservation; 
for example, one participant said, "I think of getting out of the shower a little bit sooner, because my wife gets annoyed," and another said, "My wife is a very healthy eater. She is a vegetarian; I am more or less a vegetarian just because I live with her."

These dynamics also held across adults living with other adults in non-romantic or unmarried relationships, such as adult siblings living together. One interviewee, for example, who lives with her adult sister, said, "I don't think we need to wash the clothes as much as we do but my sister has a habit of just washing them. I think she could wash twice a week instead of every other day." Another participant, who lives in a household of four related but unmarried adults ranging in age from 40 to 70 talked about norms in the home, saying:

I have three other people in this family who like to sit in a tub or take a long hot shower. Can I talk them out of it? Not if they are in aches and pains and need that to relieve their pain.

These descriptions of how others limit the ability to reduce total household consumption may involve some degree of shifting accountability to placate presumptions about the interviewer, but they also demonstrate how dynamics in a home shape overall residential resource use.

Children were, perhaps expectedly, identified as hugely influential for overall household consumption patterns. Even people without children recognized the role of children in shaping consumption; as one participant said, "It is not like we have kids that are in and out of the refrigerator all the time." Some of the influence from children has to do with household space usage. One participant with grown kids said, "We don't use the basement as much as we used to because the kids aren't really goofing around down there as much as they used to." Another said:

We bought this house with intention that all of the kids would have their own room. Three boys and now they are gone. We have a lot of extra space but in reality, the market is not in our favor right now to sell.

Others raised issues regarding resource use in a home with kids; one participant said:

Over the years we have kind of figured out that a lot of it has to do with phantom usage, we had with the kids three or four computers on at all times in the house, that sort of thing. When they moved out and we kind of adjusted that, I think that helped quite a bit.

Another said, "We always try to be aware, that we always shut off lights and yell at kids when they take 30-minute showers." The phrase phantom usage may be described as usage that has become normalized in the home to support a certain activity but only becomes apparent when the utility bill arrives or a practice is altered. The phrase appears again in a separate interview about long showers: 
It seems a little bit of a phantom, but for certain people that could say oh yeah, it is so and so in my house. Takes one-hour showers twice a day sometimes. Can't stop him, he doesn't understand, blah blah blah. There is usually some sort of a guzzler going on.

Some participants mentioned how children limit the ability to reduce the environmental impact of food consumption because they have limited food preferences; one interviewee said:

Growing up on a farm was something that made me think about my own consumption. Having kids made me think about it. I made all my own baby food when my kids were little. And then once they were able to reject all that, what did they want? They wanted Kraft macaroni and cheese. "No, I want the orange stuff, not yours." So, I did the best I could in that.

Yet another mentioned that children, even after they are grown and no longer living at home, can influence parents to engage in healthier food choices, discussed in terms of both organics and more plant-based diets. Parents were likely biased in their reporting of grown children's behavior: some were described with disappointment because they did not seem to internalize the resource conservation values their parents attempted to instill and others were described with pride as they shared knowledge and inspiration for new behaviors such as using reusable shopping bags and aiming to recycle.

The influence of spouses on household resource consumption can continue on, even after death separates those who once lived together. One participant, in describing her recent transition to being a widow and living in a new home, said, "My husband was a German and you didn't have a light on unless you were in that room. And the amount of energy [use] here [in my new home] drives me nuts." This becomes particularly salient for accurately operationalizing and modeling the role of household composition in shaping consumption behaviors, as past household characteristics not captured by contemporary data may continue to influence consumption choices. The examples of grown children and deceased spouses both suggest that attempting to realistically capture and predict consumption choices must likely account for both present and past household compositions and how they influence behaviors.

Sometimes decisions were described within the context of existing social norms and expectations, particularly within the context of family as a social institution, such as when one participant said, "Every time I eat a pork chop I feel bad actually. Maybe we go back to lentil loaf for Thanksgiving. Although I'll tell you, my family nearly killed me that year when I did that." Others even talked about the strategies they use to balance the tensions in household dynamics with regard to conservationrelated behaviors; for example, one mother was allocated the responsibility for washing laundry saying, "The easiest [thing we do to conserve resources at home], 
and this is going to sound goofy, is I do everybody's laundry, so we are not having 15 loads of two sweaters. Cause this is a thing teenage girls do." Another participant describes the difficulty when choosing between meal options, whether to eat fastfood while shuttling children around town during a busy day. They try to calculate cost, convenience, family health, and planet health saying, "Every family kind of does this equation," which also represents the allocation of managing a network of consumptive impacts. We see from this quotation that individual values can be in synergy or in conflict with others in the home which may lead to a variety of behaviors.

\section{Discussion: Incorporating household dynamics into research}

This paper echoes Shove's (2010) argument that policy-making intended to lessen the harmful environmental consequences of consumption often wrongly assumes that people are isolated individuals who make deliberative and calculative choices based on existing attitudes. Interviews with individuals about household consumption behaviors indicate that even individuals who do live alone understand how household dynamics shape resource use. Here, we argue that research on environmental decision-making could be advanced by considering how embeddedness within households shapes consumptive practices. Gaining a true understanding of the impact of household consumption on the environment requires recognition that there are vast numbers of diverse ways in which households can exist. While some consist only of nuclear family members, others include extended family or unrelated members. Yet household environmental impact, based on the amount of resources they consume in their day-to-day practices, is dependent on not only the number of members of a household but also on the dynamics between them (Ellegard \& Palm, 2015). These results strengthen the claims made by other researchers that individuals are best understood as embedded in particular social contexts that shape consumption patterns (Kennedy et al., 2009; Lutzenhiser, 1992; Spaargaren, 2003). Recognizing the impact of household dynamics is essential for building more accurate models to explain and ultimately predict resource consumption in the home. Conceptually moving away from imagery of isolated and calculative individuals, towards individuals that are embedded within household practices and processes, can improve both research design and the accuracy of research findings attempting to explain and predict environmentally consequential consumption patterns.

It is important to recognize the household's role in generating external impacts, achieving global conservation goals, and developing habits in house members. Social contexts that influence resource consumption are often defined at levels above the household, including the national level. The interaction between population and 
consumption has long been a focus of environmental research (Ehrlich, 1968; York et al., 2003). At the macro level, the STIRPAT (stochastic impacts by regression on population, affluence and technology) model illustrates that population has a multiplicative relationship with consumption and its resultant environmental impacts; for instance, a person's carbon footprint is multiplied by 5.7 for every child they have (York et al., 2002). However, assigning individual responsibility for consumption can become more difficult in group settings (Takács-Sánta, 2007). Affluence also changes the way resources are consumed, not by reducing consumption, but by shifting the sectors from which resources are consumed. An example of this shift has been observed in water usage: from the agricultural sector in developing and low socioeconomic regions to increasing usage in industrial and domestic sectors in modern developed nations (Longo \& York, 2009). Thoughtful interventions intended to shift resource consumption in the home may be able to optimize the positive output of a group of people working together to accomplish a goal if attentive to household and perhaps also community dynamics (Flint, 2010).

Other spatial and demographic factors have been shown to impact consumption. Population density, or the number of households in an area, is a stronger direct determinant of the environmental impact of consumption than population (Dietz et al., 2007; Liu et al., 2003). In addition to population and household composition, research shows that each stage in one's life course affects lifestyle choices differently, directly influencing consumption intensity (Weiss, 2000). These studies relating to consumption over the life course often focus on the commodification of a particular time in one's life course, especially in relation to young children and teenagers (Schor, 2004; Thomas, 2007). The consumption of the young is actualized by the decisions of the parents; whether to have children and how many children to have, perhaps the largest consumptive decision individuals can make (Davis, 1976). Calls have been made for the examination of gender dynamics as part of understanding environmentally consequential decision-making in the household (Kennedy \& Kmec, 2018; Niehof, 2011). In a consumer culture, parenting is often reduced to provisioning. Across social classes, there is a "commercialization of childhood" resulting from media and corporate marketing aimed at children (Schor, 2004). The overwhelming social pressure to participate in child-rearing, especially for women, along with the fact that the measure of good parenting has been reduced to what parents provide their children (Wilson \& Wood, 2004), illustrates how the socially constructed institution of the family, as embedded in household consumption dynamics, can create environmentally damaging positive feedback loops.

Yet as Cook (2008) argues, children are not perfectly socialized extra expenses, but rather active co-participants in the consumption experience, capable of influencing parents to shift consumption to reduce its environmental impact (Damerell, et al., 2013). Thinking of children as merely inputs into individually comprised consumer decisions inadequately captures their role in shaping consumption behaviors in 
the home. Pets are another consumer within the home that are dependent on the decision-making of the household. Pets and domesticated animals are overlooked by traditional sociological measurements of individual consumption yet are considered to function as part of the family by much of the public (Cohen, 2002). Pets and animals are also capable of sparking ethical revelations that result in the changed behavior of their human families (Hribal, 2007). Rather than conceptualizing consumptive practices in the home as the result of the head of the household's decisions, it is more accurate to consider a range of humans, nonhumans, pets, plants, appliances, and microbes as cocreators of consumption (Latour, 2004; Strengers et al., 2016).

Studies of individuals' environmentally responsible behavior typically proceed on the assumption that individual norms, values, beliefs, or knowledge are the predominant influences on behavioral choices (e.g., Ajzen, 1991; Shwom \& Lorenzen, 2012). Accurately predicting environmentally responsible consumer choices requires moving beyond this assumption, as Shove (2010) describes, to consider choices within the context of household dynamics (this study) and systems of provision (as discussed in scholarship on theories of practice: see Spaargaren, 2003) as well as the regional resource context (including resource availability and the policies that shape it). Research on environmental decision-making can be improved by incorporating both the challenges and the opportunities provided by household dynamics and characteristics. Recognizing household norms that govern current consumptive practices also sheds light on the transmission of behaviors across time and generations (Kleinschafer \& Morrison, 2013). Environmental policy-making may also be improved by moving away from the imagery of the isolated individual, perhaps by including decision-making and consumptive processes like the five listed in Table 1 (Shove, 2010).

The compositions of households differ around the world and are dynamic. It is important to formalize the study of these factors as they relate to environmentally consequential decision-making. Many countries project that their number of single-person households will grow significantly by 2030, with numerous European countries having 40 percent of their households being comprised of single-person households (OECD, 2011). In the next 10-15 years, the number of couples without children will increase across most of the countries that participate in Organisation for Economic Co-operation and Development (OECD) data collection and projections. Immigration is expected to increase in European countries as well as the United States. Degraded environments can act as the catalyst for migration as well as be the outcome of migration.

According to projections, migration and high fertility levels will increase the percentage of minorities in these countries and, in the case of the United States, minority groups will become the largest groups within the next three decades. Changes in marriage, fertility, life expectancy, and employment demographics 
create unknowns for intergenerational living, cohabitation, family composition, and household dynamics (OECD, 2011). An advantage of setting the research frame at the household level is that shifts in social structures within households can be captured within future data (Niehof, 2011).

Data procurement and analysis considering household dynamics may be collected from an individual within the household, a representative of the household, or from every individual within the household. An individual's perceived role within the research study and household may influence their responses to survey and interview questions (Bowen et al., 2019). Yet participants would likely be able to ascribe household behavioral patterns related to themselves and others within their household as active spenders, conscious occupiers, average users, conservers, and inactive users (Ben \& Steemers, 2018). Pairing those data with demographic information about household compositions would provide a richer landscape for understanding household consumption. Utilizing that information may allow for exploration of household practices that would right-size consumption, valuable in understanding the ever-changing projections for household composition where no factor exists as a constant. A drawback to this approach is the amount of time required by researchers and participants to share information. Institutional review boards also have individuals as a focus, rather than households, making data collection on a group which may contain minors an added challenge.

\section{Conclusion}

Viewing consumption as not only shaped by individual attitudes and behaviors but also by the composition and dynamics of life within the home sheds light on how the social institutions that structure our lives may act to shape the environmental impacts of resource consumption (Ellegård \& Palm, 2015). These dynamics are often but not always connected to the social institution of the family and remain influential even when the household has changed. Taking the household seriously also moves farther from the rational actor paradigm, with its assumptions of individuals making planned or rational choices (Ajzen, 1991; Shwom \& Lorenzen, 2012). The individual may perceive themselves to have limited agency or efficacy for practicing environmentally responsible behaviors, based on both household dynamics and societal limitations (Kennedy et al., 2009). Unfortunately, research focused on individual values as predictive of individual behaviors may act to reinforce these limitations rather than promote collective action within and beyond the home. Conceptual approaches that consider individuals as isolated decisionmakers introduce flaws into research design, data collection, and analyses. Future studies of environmentally consequential household practices may be able to more fully account for the constellation of influences that shape consumption decisions by situating an individual within the context of their household, as we have done by 
identifying five processes that influence consumption: (1) preferring, (2) norming, (3) enhancing, (4) constraining, and (5) allocating. Researchers can more clearly explain and ultimately seek to change behaviors in order to lessen the damaging consequences of human consumptive practices on the resources required to sustain current and future human lives by understanding social dynamics within the home.

\section{References}

Ajzen, I. (1991). The theory of planned behavior. Organizational behavior and human decision processes, 50(2), 179-211. doi.org/10.1016/0749-5978(91)90020-t

Bamberg, S., \& Möser, G. (2007). Twenty years after Hines, Hungerford, and Tomera: A new meta-analysis of psycho-social determinants of pro-environmental behaviour. Journal of Environmental Psychology, 27(1), 14-25. doi.org/10.1016/j.jenvp.2006.12.002

Becker, H. S. (1998). Tricks of the trade. University of Chicago Press.

Ben, H., \& Steemers, K. (2018). Household archetypes and behavioural patterns in UK domestic energy use. Energy Efficiency, 11(3), 761-771. doi.org/10.1007/s12053-0179609-1

Black, J. S., Stern, P. C., \& Elworth, J. T. (1985). Personal and contextual influences on household energy adaptations. Journal of Applied Psychology, 70(1), 3-21. doi.org/10.1037/ 0021-9010.70.1.3

Bowen, S., Brenton, J., \& Elliott, S. (2019). Pressure cooker: Why home cooking won't solve our problems and what we can do about it. Oxford University Press.

Charmaz, K. (2014). Constructing grounded theory. Sage.

Chow, J., Kopp, R. J., \& Portney, P. R. (2003). Energy resources and global development. Science, 302(5650), 1528-1531. doi.org/10.1126/science.1091939

Cohen, S. P. (2002). Can pets function as family members? Western Journal of Nursing Research, 24(6), 621-638. doi.org/10.1177/019394502320555386

Cook, D. T. (2008). The missing child in consumption theory. Journal of Consumer Culture, 8(2), 219-243. doi.org/10.1177/1469540508090087

Damerell, P., Howe, C., \& Milner-Gulland, E. J. (2013). Child-orientated environmental education influences adult knowledge and household behaviour. Environmental Research Letters, 8(1). doi.org/10.1088/1748-9326/8/1/015016

Davis, H. L. (1976). Decision making within the household. Journal of Consumer Research, 2(4), 241-260. doi.org/10.1086/208639 
Dietz, T., Gardner, G. T., Gilligan, J., Stern, P. C., \& Vandenbergh, M. P. (2009). Household actions can provide a behavioral wedge to rapidly reduce US carbon emissions. Proceedings of the National Academy of Sciences, 106(44), 18452-18456. doi.org/10.1073/ pnas.0908738106

Dietz, T., Rosa, E. A., \& York, R. (2007). Driving the human ecological footprint. Frontiers in Ecology and the Environment, 5(1), 13-18. doi.org/10.1890/1540-9295(2007)5 [13:dthef]2.0.co;2

Ehrlich, P. R. (1968). The population bomb. Ballantine Books.

Ellegård, K., \& Palm, J. (2015). Who is behaving? Consequences for energy policy of concept confusion. Energies, 8(8), 7618-7637. doi.org/10.3390/en8087618

Fishbein, M., Jaccard, J., Davidson, A. R., Ajzen, I., \& Loken, B. (1980). Predicting and understanding family planning behaviors. In I. Ajzen, \& M. Fishbein (Eds.), Understanding attitudes and predicting social behavior (pp. 132-147). Prentice-Hall.

Flint, R. W. (2010). Seeking resiliency in the development of sustainable communities. Human Ecology Review, 17(1), 44-57. www.jstor.org/stable/24707514

Heberlein, T. A. (2012). Navigating environmental attitudes. Oxford University Press. doi.org/ 10.1093/acprof:oso/9780199773329.001.0001

Hines, J. M., Hungerford, H. R., \& Tomera, A. N. (1987). Analysis and synthesis of research on responsible environmental behavior: A meta-analysis. The Journal of Environmental Education, 18(2), 1-8. doi.org/10.1080/00958964.1987.9943482

Holdert, F., \& Antonides, G. (1997). Family type effects on household members' decision making. In M. Brucks \& D. J. MacInnis (Eds.), NA-Advances in consumer research (Vol. 24; pp. 48-54). Association for Consumer Research. www.acrwebsite.org/volumes/ $8007 /$ volumes/v24/na-24

Hribal, J. C. (2007). Animals, agency, and class: Writing the history of animals from below. Human Ecology Review, 14(1), 101-112. www.jstor.org/stable/24707647

Kennedy, E. H., Beckley, T. M., McFarlane, B. L., \& Nadeau, S. (2009). Why we don't "walk the talk": Understanding the environmental values-behaviour gap in Canada. Human Ecology Review, 16(2), 151-160. www.jstor.org/stable/24707539

Kennedy, E. H., \& Kmec, J. (2018). Reinterpreting the gender gap in household proenvironmental behaviour. Environmental Sociology, 4(3), 299-310. doi.org/10.1080/ 23251042.2018 .1436891

Kleinschafer, J., \& Morrison, M. (2013). Household norms and their role in reducing household electricity consumption. International Journal of Consumer Studies, 38(1), 75-81. doi.org/10.1111/ijcs.12066

Latour, B. (2004). Nonhumans. In S. Harris, S. Pile, \& N. Thrift (Eds.), Patterned ground: Entanglements of nature and culture (pp. 224-227). Reaktion Books. 
Liu, J., Daily, G. C., Ehrlich, P. R., \& Luck, G. W. (2003). Effects of household dynamics on resource consumption and biodiversity. Nature, 421(6922), 530-533. doi.org/10.1038/ nature 01359

Longo, S. B., \& York, R. (2009). Structural influences on water withdrawals: An exploratory macro-comparative analysis. Human Ecology Review, 16(1), 75-83. www.jstor.org/stable/ 24707738

Lutzenhiser, L. (1992). A cultural model of household energy consumption. Energy, 17(1), 47-60. doi.org/10.1016/0360-5442(92)90032-u

Niehof, A. (2011). Conceptualizing the household as an object of study. International Journal of Consumer Studies, 35(5), 488-497. doi.org/10.1111/j.1470-6431.2011.01026.x

OECD. (2011). The future of families to 2030: Projections, policy challenges, and policy options. A synthesis report. Organisation for Economic Co-operation and Development. www. oecd.org/futures/49093502.pdf

OECD. (2016). National accounts at a glance 2015 [Data set]. Organisation for Economic Co-operation and Development. stats.oecd.org/Index.aspx?DataSetCode=NAAG

Schor, J. B. (2004). Born to buy: The commercialized child and the new consumer culture. Scribner.

Sebastian, K. (2019). Distinguishing between the strains grounded theory: Classical, interpretive and constructivist. Journal for Social Thought, 3(1). ojs.lib.uwo.ca/index.php/ jst/article/view/4116

Sharma, S., \& Ruud, A. (2003). On the path to sustainability: Integrating social dimensions into the research and practice of environmental management. Business Strategy and the Environment, 12(4), 205-214. doi.org/10.1002/bse.366

Shove, E. (2010). Beyond the ABC: Climate change policy and theories of social change. Environment and Planning A: Economy and Space, 42(6), 1273-1285. doi.org/10.1068/ a42282

Shwom, R., \& Lorenzen, J. A. (2012). Changing household consumption to address climate change: Social scientific insights and challenges. Wiley Interdisciplinary Reviews: Climate Change, 3(5), 379-395. doi.org/10.1002/wcc.182

Spaargaren, G. (2003). Sustainable consumption: A theoretical and environmental policy perspective. Society and Natural Resources, 16(8), 687-701. doi.org/10.1080/ 08941920309192

Spaargaren, G., Lamers, M., \& Weenink, D. (2016). Introduction: Using practice theory to research social life. In G. Spaargaren, M. Lamers, \& D. Weenink (Eds.), Practice theory and research: Exploring the dynamics of social life (pp. 3-27). Routledge. doi.org/10.4324/ 978131565690 
Staats, H., Harland, P., \& Wilke, H. A. M. (2004). Effecting durable change: A team approach to improve environmental behavior in the household. Environment and Behavior, 36(3), 341-367. doi.org/10.1177/0013916503260163

Stern, P. (2014). Individual and household interactions with energy systems: Toward integrated understanding. Energy Research \& Social Science, 1, 41-48. doi.org/10.1016/ j.erss.2014.03.003

Strengers, Y., Nicholls, L., \& Maller, C. (2016). Curious energy consumers: Humans and nonhumans in assemblages of household practice. Journal of Consumer Culture, 16(3), 761-780. doi.org/10.1177/1469540514536194

Takács-Sánta, A. (2007). Barriers to environmental concern. Human Ecology Review, 14(1), 26-38. www.jstor.org/stable/i24707637

Thomas, S. G. (2007). Buy, buy baby: How consumer culture manipulates parents and harms young minds. Houghton Mifflin Harcourt.

United States Census Bureau. (2018). U.S. Census Bureau releases 2018 families and living arrangements tables [Press Release]. www.census.gov/newsroom/press-releases/2018/ families.html

Warde, A. (2005). Consumption and theories of practice. Journal of Consumer Culture, 5(2), 131-153. doi.org/10.1177/1469540505053090

Watkins, D., Shwom, R., Schelley, C., Agusdinata, D. B., Floress, K., \& Halvorsen, K. E. (2019). Understanding household conservation, climate change and the food-energy-water nexus from a transdisciplinary perspective. In K. E. Halvorsen, C. Schelly, R. M. Handler, E. C. Pischke, \& J. L. Knowlton (Eds.), A research agenda for environmental management (pp. 145-158). Edward Elgar Publishing. doi.org/10.4337/9781788115193.00023

Weiss, M. J. (2000). The clustered world: How we live, what we buy, and what it all means about who we are. Little, Brown and Company.

Wilson, C., \& Dowlatabadi, H. (2007). Models of decision making and residential energy use. Annual Review of Environment and Resources, 32(1), 169-203. doi.org/10.1146/ annurev.energy.32.053006.141137

Wilson, G., \& Wood, K. (2004). The influence of children on parental purchases during supermarket shopping. International Journal of Consumer Studies, 28(4), 329-336. doi.org/ 10.1111/j.1470-6431.2004.00393.x

York, R., Rosa, E. A., \& Dietz, T. (2002). Bridging environmental science with environmental policy: Plasticity of population, affluence, and technology. Social Science Quarterly, 83(1), 18-34. doi.org/10.1111/1540-6237.00068

York, R., Rosa, E. A., \& Dietz, T. (2003). Footprints on the earth: The environmental consequences of modernity. American Sociological Review, 68(2), 279-300. doi.org/ $10.2307 / 1519769$ 
This text is taken from Human Ecology Review, Volume 26, Number 1, 2020, published by ANU Press, The Australian National University, Canberra, Australia. doi.org/10.22459/HER.26.01.2020.10 